\title{
LA INTENSIFICACIÓ RETÒRICA DELS ELEMENTS MORBOSOS EN LES FAULES MITOLÒGIQUES DE JOAN ROÍS DE CORELLA: DE LA IMITATIO A LA INNOVACIÓ ESTETICA
}

\author{
Rafael Alemany Ferrer \\ rafael.alemany@ua.es \\ Universitat d'Alacant
}

Tot i tractar-se d'obres primerenques ${ }^{1}$, o potser precisament per això, les narracions mitològiques ${ }^{2}$ de Joan Roís de Corella (Gandia, 1435 -València, 1497) ${ }^{3}$ palesen la pràctica totalitat dels trets estètics i conceptuals ${ }^{4}$ que caracteritzen el conjunt de la seua obra diversa i prolixa $^{5}$. Aquestes s'inscriuen en l'òrbita dels exercicis d'escriptura mitjançant els quals els joves amb vocació literària s'ensinistraven en l'art de la composició en prosa, experimentaven en les diverses modalitats textuals i descobrien les possibilitats expressives de la retòrica. El mètode consistia, substancialment, a reescriure un tema ja desenvolupat prèviament per autors anteriors de prestigi, però amb ingredients personals al servei d'un determinat propòsit i d'una inequívoca voluntat d'estil. Com assenyala Josep Pujol:

${ }^{1}$ Vid. Stefano M. Cingolani, «D’Aquil·les a Jesús. Reflexions sobre la cronologia de les obres de Joan Roís de Corella», Anuari de l'Agrupació Borrianenca de Cultura, 8 (1997), pp. 67-85.

${ }^{2}$ A més de l'antiga edició de Ramon Miquel i Planas dins Obres de Joan Roís de Corella (Barcelona, 1913), disposem de la de Josep Lluís Martos, Les proses mitològiques de Joan Roís de Corella, Alacant / Barcelona, Institut Interuniversitari de Filologia Valenciana / Publicacions de l'Abadia de Montserrat, 2001. Vid. també, fonamentalment, els estudis de Josep Lluís Martos, Fonts i seqüència cronològica de les proses mitològiques de Joan Roís de Corella, Alacant, Departament de Filologia Catalana de la Universitat d'Alacant, 2001, per una part, i, per l'altra, d'Annamaria Annicchiarico, «L'edizione critica delle Faules mitologiche di Joan Roís de Corella: bilanci, sondaggi, proposte», La Parola del Testo. Semestrale di Filologia e Letteratura Europea dalle Origini al Renascimento, 8 (=Studi in Onore di Giuseppe E. Sansone, 2), 2004, pp. 443-466.

${ }^{3}$ Per a una biografia actualitzada de l'aquest escriptor, vid. Abel Soler, Joan Roís de Corella (1435-1497). Síntesis biogràfica i aportació documental, València, Acadèmia Valenciana de la Llengua, 2014. També es pot veure la síntesi de Jaume J. Chiner Gimeno, «L'autor», dins la Biblioteca d'Autor dedicada a Joan Roís de Corella en la Biblioteca Virtual Miguel de Cervantes, <http://www.cervantesvirtual.com/portales/rois_de_corella/autor/> [consulta: 25/06/2014].

${ }^{4}$ Vid. Stefano M. Cingolani, Joan Roís de Corella: la importància de dir-se honest, València, Tres i Quatre, 1988.

${ }^{5}$ Per a una aproximació de conjunt a aquesta, vid. Tomàs Martínez Romero, «L'obra literària», dins la Biblioteca d'Autor dedicada a Joan Roís de Corella en la Biblioteca Virtual Miguel de Cervantes, $<$ http://www.cervantesvirtual.com/portales/rois_de_corella/obra_catalogo/> [consulta: 25/06/2014]. 
Si les traduccions al vulgar incorporen les tècniques del comentari i la glossa, la pràctica literària tardomedieval depèn també de models i de tècniques gramaticals i retòrics basats en la imitatio dels auctores. L'ensenyament de la gramática i la retòrica es fonamenta en la lectura comentada dels autors del cànon (l'enarratio poetarum) i en l'aplicació creativa que consisteix a compondre nous textos que reprenen imitativament els models i els varien retòricament gràcies als coneixements adquirits de les dues disciplines ${ }^{6}$.

Nogensmenys és el que fa Roís de Corella en les seues faules mitològiques, en les quals recrea diversos motius temàtics de filiació clàssica -les Metamorfosis i les Heroides d'Ovidi', la Historia destructionis Troiae de Guido delle Colonne ${ }^{8}$, les Troades de Sèneca....àmpliament difosos al llarg de l'edat mitjana, amb propòsit moral, a través de traductors i adaptadors ${ }^{10}$, entre els quals ocupa un lloc

\footnotetext{
${ }^{6}$ Josep Pujol, «Expondre, traslladar i reescriure clàssics llatins en la literatura catalana del segle Xv», Quaderns. Revista de Traducció, 7 (2002), pp. 9-32, la cita en p. 17.

${ }^{7}$ Les Heroides d'Ovidi ja havien estat traduïdes al català, molt probablement, per Guillem Nicolau, rector de Maella, a finals del s. xIV; se'n conserva un manuscrit en la Biblioteca Nacional de França. El 1494 es publica, per la seua part, la versió catalana de Francesc Alegre de les Metamorfosis ovidianes amb el nom de Transformacions, acompanyada d'una interpretació al·legòrica cristiana, a la manera del que fa Boccaccio en les Genealogiae deorum gentilium (Francesc Alegre, Transformacions, Barcelona, Pere Miquel, 1494); per raons cronològiques, però, no és probable que Roís de Corella utilitzara aquesta última versió. Vid. Lola Badia, «Per la presència d'Ovidi a l'Edat Mitjana, amb notes sobre les traduccions de les Heroides i de les Metamorfosis al vulgar», dins Studia in honorem prof. M. de Riquer, Barcelona, Quaderns Crema, 1986, vol. I, pp. 75-93 [reed. corregida dins Lola Badia, Tradició i modernitat als segles XIV i XV. Estudis de cultura literària i lectures d'Ausiàs March, València / Barcelona, Institut Interuniversitari de Filologia Valenciana / Publicacions de l'Abadia de Montserrat, 1993, pp. 39-71]; Lluís Lucero Comas, «La tradició ovidiana en l'obra de Joan Roís de Corella: una aproximació parcial», dins Mercè Puig Rodríguez-Escalona (ed.), Tradició clàssica. Actes de l'XI Simposi de la Secció Catalana de la SEEC (1993), Andorra la Vella, Govern d'Andorra, Conselleria d'Educació, Joventut i Esports, 1996, pp. 437-442; E. Trilla Millàs i V. Cristóbal López, «Las Heroidas de Ovidio en Joan Roís de Corella», dins Mercè Puig Rodríguez-Escalona (ed.), Tradició clàssica. Actes de l'XI Simposi de la Secció Catalana de la SEEC (1993), Andorra la Vella, Govern d'Andorra, Conselleria d'Educació, Joventut i Esports, 1996, pp. 693-697.

${ }^{8}$ Escrita en llatí el 1287 per Guido delle Colonne i traduïda al català per Jaume Conesa el s. XIV: Les Històries Troyanes de Guiu de Columpnis, traduides al català en el $\mathrm{XIV}^{\text {èn }}$ segle per en Jacme Conesa y ara per primera volta publicades, ed. Ramon Miquel i Planas, Barcelona, Casa Miquel-Rius, 1916; a hores d'ara, Joan M. Perujo, de la Universitat d'Alacant, n'ha ultimat (2015) una edició crítica. Per al reciclatge d'aquesta obra per part de Joan Roís de Corella, vid. Josep Lluís Martos, «La Historia destructionis Troiae como fuente de las prosas mitológicas de Joan Roís de Corella», dins L. von der Walde, C. Company i A. González (eds.), Literatura y conocimiento medieval. Actas de las VIII Jornadas Medievales, México, Universidad Nacional Autónoma de México / Universidad Autónoma Metropolitana / El Colegio de México, 2003, pp. 297-327.

${ }^{9}$ L. A. Sèneca, Tragèdies. Traducció catalana medieval amb comentaris del s. XIV de Nicolau Trevet, 2 vols., ed. Tomàs Martínez Romero, Barcelona, Barcino, 1995.

${ }^{10} \mathrm{La}$ tradició exegètica dels mites clàssics s'inicia amb els Commentarii in Vergilii Aeneida de Servi (s. IV) (Servii Grammatici qui feruntur in Vergilii Carmina Commentarii, 2 vols., ed. Georgius Thilo, Hildesheim, Georg Olms Verlagsbuchhandlung, 1961), i amb les Mitologiae de Fulgenci (ss. V-VI) -la compilació més important d'època tardoantiga- (Fabius Planciadius Fulgentius, Opera [1970], ed. R. Helm, Stuttgart, Teubner, 1989), i es desenvolupa
} 
privilegiat Boccaccio ${ }^{11}$. Però en el nostre autor,

el resultat de l'aplicació al català d'aquestes tècniques escolars són uns textos nous de trinca que, fins i tot quan hi ha proximitat literal a la font, ja no aspiren a facilitar l'accés a l'original, sinó a substituirlo i a imposar-se com a producció textual diferent i amb drets propis. $\mathrm{Si}$, a més, tenim en compte l'orientació moral amb què recrea els models clàssics, Corella resulta un magnífic exemple de la relació entre traducció, comentari i invenció retòrica $[\ldots]^{12}$.

Les proses mitològiques estan constituïdes per quatre textos basats en la matèria de la guerra de Troia -Lletra fingida que Aquil.les escriu a Políxena, Raonament de Telamó i d'Ulisses, Plant dolorós de la reina Hècuba i Lo jui de Paris-, la Lamentació de Biblis, la trilogia formada per les Lamentacions de Mirra, Narciso i Tisbe -que Miquel i Planas, primer editor de Roís de Corella ${ }^{13}$, titulà Lo jardi d'amor-, La història de Leandre i Hero, la lletra de Medea a les dones i el Parlament en casa de Berenguer Mercader, que, al seu torn, inclou la recreació de cinc mites: el de Cèfal i Procris, el d'Orfeu, el d'Escil·la, el de Pasífae i el de Tereu, Procne i Filomela.

En termes generals, el nostre autor aprofita el material mitològic en què s'inspira amb un propòsit edificant $\mathrm{i}$ força ajustat a la moral cristiana. En realitat, aquest objectiu no havia de resultar-li gaire difícil perquè, al capdavall, tant aquests com tots els mites, siguen pagans, cristians o de qualsevol altra cultura, permeten sempre una lectura moral, com bé demostren, entre d'altres, Boccaccio o Francesc Alegre. Consegüentment, l'interés primordial d'aquests textos corellans rau no tant en les obligades i mínimes adaptacions dels mites pagans a la cultura cristiana tardomedieval, com en la reformulació

en la tardor medieval amb les recopilacions dels tres Mitògrafs Vaticans -que conformen un repertori basat fonamentalment en Servi i que foren confegits, si més no el primer, entre els segles IX i XI- i les Genealogiae deorum gentilum (1350-55) de Giovanni Boccaccio - nexe de transició al Renaixement i primer repertori mitogràfic que no barreja els mites llegendaris amb interpretacions morals, les quals s'exposen clarament diferenciades a la fi de cada mite(Giovanni Boccaccio, Genealogie delorum gentilium libri, 2 vols., Vincenzo Romano (ed.), Bari, Gius Laterza i figli, 1951), o amb textos del s. XIV com l'Ovidius moralizatus, de Pierre de Bersuire (Petrus Berchorius, Ovidius moralizatus, Joseph Engels (ed.), Werkmateriaal-2, Utrecht, 1966) i l'anònim francés Ovide moralisé (Ovide moralisé. Poème du commencement du XIV siècle, publié d'après tous les manuscrits connus, 5 vols., Charles de Boer (ed.), Amsterdam, Johannes Müller, 1915-38), l'últim dels quals fou objecte d'una prosificació en el s. $\mathrm{xv}$ (Ovide moralisé en prose (texte de quinxième siècle), Charles de Boer (ed.), Amsterdam, North-Holland Publishing Company, 1954).

${ }^{11}$ Vid. Josep Lluís Martos, «Boccaccio y Joan Roís de Corella: las Genealogiae deorum», Cuadernos de Filología Italiana, número extraordinari, (2001), pp. 535-557, i, del mateix autor, «La presència de Boccaccio en les proses mitològiques de Joan Roís de Corella», dins Anna Maria Compagna Perrone Capano, Alfonsina De Benedetto i Nuria Puigdevall (eds.), Momenti di Cultura Catalana in un Millennio. Atti del VII Convegno dell'AISC (Napoli, 22-24 maggio 2000), Nàpols, Liguori Editore, 2003, vol. 1, pp. 263-294.

${ }^{12}$ Josep Pujol, art. cit., p. 17.

${ }^{13}$ Edició citada en n. 2. 
d'aquests en una llengua literària molt elaborada i farcida de virtuosisme retòric, capaç d'emular l'estil elevat que requerien els temes tractats i del qual ja havien fet ús els autors antics que l'autor valencià prenia com a models de referència. En paraules d'Alan Deyermond, «Corella va aconseguir transformar el material ovidià en una nova manera de contar històries ben conegudes $\rangle^{14}$.

La col·lecció de relats mitològics corellans constitueix un ric repertori d'històries morboses que protagonitzen personatges turmentats per una passió malaltissa o irrefrenable, com ara Biblis i Mirra, enamorades, respectivament, del seu germà i del seu pare; o mares que, com Medea i Procne, maten el seus propis fills per venjar-se dels seus marits infidels; o dones com Escil-la, que no dubta a matar el seu pare, convençuda, equivocadament, que això agradarà al seu enamorat, o com Pasífae, que manté relacions sexuals adulterines amb una bèstia, $o$, en fi, homes com Tereu, que, després de violar la seua cunyada, li talla la llengua perquè aquesta no el puga delatar. Per altra part, les conseqüències funestes de la mateixa passió amorosa, exemplificades en el rapte d'Helena per Paris, es reflecteixen en el desenllaç de la guerra de Troia que evoca en el seu Plant patètic la reina Hècuba, amb referència especial a l'ajusticiament del seu marit, el rei Príam, de la seua filla Políxena i del seu nét Astíanax. No exagera, doncs, Lola Badia quan diu que, per al nostre autor, «l'amor és tan sols l'explosió criminal del desig de la carn ${ }^{15} \mathrm{i}$, per això, el que intenta és convéncer «el seu públic de l'extrema maldat de l'amor i de la conveniència d'evitar-lo» ${ }^{16}$.

És evident, doncs, que Roís de Corella opta per reescriure assumptes antics d'elevat alé tràgic i d'inevitable rerefons morbós. Però no és en aquest tipus de temes que pretenem centrar-nos ací, sinó en un tret estilístic peculiar com és la tendència al detallisme narrativodescriptiu en les seqüències més específicament morboses d'aquests relats. Aquest tret suposa una clara innovació estètica de l'autor en la mesura que o bé no es constata en els models literaris en què es basa, o bé hi apareix reduït a la mínima expressió. La complaença a descendir al detall descriptiu d'esdeveniments desagradables o que provoquen reaccions mentals insanes és, sens dubte, un ingredient més de l'estètica de l'exacerbació patètica i de l'efectisme per la qual aposta decididament el nostre escriptor.

Centrarem la nostra anàlisi en alguns dels nuclis de major intensitat tràgica d'una selecció representativa de les proses mitològiques:

\footnotetext{
${ }^{14}$ Alan Deyermond, «Prefaci», dins Josep Lluís Martos, Fonts $i$ seqüència cronològica de les proses mitolòiques de Joan Roís de Corella, op. cit., p. 8.

${ }^{15}$ Lola Badia, «En les baixes antenes de la vulgar poesia: Corella, els mites i l'amor», dins Lola Badia, De Bernat Metge a Joan Roís de Corella. Estudis sobre la cultura literària de la tardor medieval catalana, Barcelona, Quaderns Crema, 1988, pp. 145-181, la cita en p. 165.

${ }^{16}$ Lucero Comas, art. cit., p. 438.
} 
el Plant, la lletra de Medea, la lamentació de Mirra i, finalment, la història de Pasífae i la de Tereu, Procne i Filomela del Parlament.

\section{El PlaNT DOLORÓS DE LA REINA HÈCUBA}

La reina de Troia, mitjançant un relat exaltat i declamatori en primera persona, fet més «des d'una perspectiva familiar i materna que no pas històrica ${ }^{17}$, narra les horribles situacions que es van viure al seu reialme en els moment finals de la guerra amb els grecs i, especialment, les morts del seu marit, de la seua filla i del seu nét. Com a fonts principals de referència han estat assenyalades les Metamorfosis d'Ovidi (XIII, vv. 399-481) ${ }^{18}$, les Troades de Sèneca (fonamentalment els actes 4t i 5é) $)^{19}$, Les històries troianes (llibre XXXX) ${ }^{20}$ i les Genealogiae deorum gentilium (VI, 24) ${ }^{21}$.

El Plant consta de set seqüències susceptibles d'anàlisi des de la perspectiva de la intensificació morbosa: la descripció del paisatge resultant després de la desfeta final de Troia, l'evocació de la humiliació a què va ser sotmés el cos mort d'Hèctor, la mort de Príam, la súplica d'Hècuba a Pirros perquè la mate, la profecia de Cassandra sobre la destrucció de Troia, la mort de Políxena i la mort d'Astíanax.

\section{a) El panorama posterior a la desfeta}

La primera seqüència és la macabra descripció del paisatge que es pot divisar des d'un coll després de la devastació de Troia:

staven no mesclats en nombre sens compte los cossors, acompanyats de ossos de la consumpta carn ja despullats [...].

[...] Y en diverses esquadres als vius paria que ells, morts, desigada batalla speraven. Fins que multitud de diversos oszells en companyia de animals salvatges, dels ossos la carn despullant, mobles e volants sepultures los donaven, perquè semblant a la inquieta vida fos llur darrera sepultura. Los ossos dels quals, si una flama emsemps cremar asajava, com la umida sal, ab so spantable, los uns dels altres ab velocitat no poqua s'apartaven (p. 138) 22 .

Aquestes imatges colpidores - cossos morts dels combatents grecs i troians, que, malgrat haver estat ja devorats per ocells rapinyaires i altres bèsties, encara semblen palesar el seu odi-, són impossibles

\footnotetext{
${ }^{17}$ Stefano M. Cingolani, Joan Roís de Corella..., cit., p. 13.

${ }^{18}$ Publi Ovidi Nasó, Les metamorfosis, 3 vols., ed. i trad. catalana d'Adela M. Trepat i Anna M. de Saavedra, Barcelona, Fundació Bernat Metge, 1929-32.

${ }^{19}$ Sèneca, op. cit.

${ }^{20} \mathrm{Op}$. cit.

${ }^{21}$ Boccaccio, op. cit.

${ }^{22}$ Tant aquesta citació com la de la resta de citacions dels textos de Roís de Corella que apareixen en aquest article remeten sempre a Josep Lluís Martos (ed.), Les proses mitològiques de Joan Roís de Corella, op. cit.
} 
de trobar en cap de les fonts indicades, ni tan sols en el passatge de les lamentacions d'Hècuba i del cor de dones troianes que trobem en l'acte primer de les Troades de Sèneca ${ }^{23}$, considerat, des de l'edició corellana de Miquel i Planas ${ }^{24}$, com a font d'inspiració general d'aquesta primera seqüència del Plant.

\section{b) L'evocació de la humiliació del cadàver d'Hèctor}

En la segona seqüència, Hècuba es fa ressò de la humiliació a què va ser sotmés el cadàver d'Hèctor per part del bàndol grec,

quant lo cors sens ànima de aquest fill meu, pare de cavalleria, fon roseguat por los nostres e seus camps troyans, ligat a la coha del cavall de Achilles, laurant la terra a l'entorn dels murs de la sua ciutat en presència de sos vassals (p. 140).

Aquesta seqüència és menys original, però és interessant assenyalar com, de les dues fonts que l'autor té a l'abast per a confegir-la, tria la més impactant des d'un punt de vista emocional. En efecte, l'al'lusió a l'arrossegament del cadàver d'Hèctor amarrat a un carro conduït per Aquil·les, absent en Les històries troianes, la trobem en l'acte IV de les Troades, si bé posada en boca de la seua víuda Andròmaca i no pas en la de la seua mare Hècuba:

Troya és cayguda ara de present a vosaltres, mas a mi gran temps ha qui· $\mathrm{m}$ caygué. Car com Axil-les anant damunt un carro roçegava detràs si lo cors de Èctor-de què lo meu cors se rocegava-e la roda del dit carro gemecava ab gran so e brugit, tremolosa per lo càrrech gran de Èctor, qui tirava detràs ffort cruelment e soptosa, llavors caygué e ffon a mi aterrada Troya ${ }^{25}$.

I també la podem documentar en les Genealogiae deorum gentilium (VI, 24):

Y no mucho después, llegado al encuentro con Aquiles, bien porque Héctor estuviese fatigado o porque Aquiles fuera más fuerte, cayó vencido por Aquiles y no sólo fue despojado de las armas y del restante ornato por el vencedor, sino que fue arrastrado por el carro con el tahalí regalado por Ayax alrededor de Ilio, viéndolo Príamo $[\ldots]^{26}$.

\footnotetext{
${ }^{23}$ Sèneca, op. cit., II, pp. 339-346.

${ }^{24}$ Obres de Joan Roiç de Corella, cit., p. LIV.

${ }^{25}$ Sèneca, op. cit., II, p. 358.

${ }^{26}$ Giovanni Boccaccio, Genealogía de los dioses paganos, trad. española de M. Consuelo Álvarez i Rosa M. Iglesias, Madrid, Editora Nacional, 1983, p. 389.
} 
És evident que Joan Roís de Corella s'acosta molt més al model subministrat per les Troades, pel seu major efectisme en relació al text de Boccaccio, tot i que encara el supera amb intensitat dramàtica quan es refereix a l'ús del cadàver com a eina per a llaurar la terra que envoltava els murs de la ciutat, d'una banda, i al fet que això es feia, per a una major humiliació, als ulls dels qui havien estat els seus vassalls.

\section{c) La mort de Príam}

El tercer nucli és l'assassinat de Príam a mans de Pirros, fill d'Aquil·les, que el mata amb la seua espasa. Roís de Corella ens descriu l'escena amb tot luxe de detalls morbosos:

amaguant la tallant spasa en lo seu envellit, dèbil e ruat coll, la qual, per no tornar per lo camí hon entrada era, acabà tallar aquella part poqua que del primer colp restava. Prenent aquells blanchs cabells ab la mà squerra, los quals la daurada reyal corona de tota Àsia en triümpho de gran majestat aplanats havia, caigué sens cap, com a tronch envellit, lo cors del rey, cobrint los pahiments de nostra real cambra de tapits carmesins, tints de sangonosa porpra en tan gran habundància, que les òrfenes filles llurs peus no podien fer stalvis que en la corrent sanch de Príam no·s banyassen.

Romania lo cap penjat en la mà dels cruel carnicer, lo qual, obrint la finestra, cridant deya:

«O, troyans! Preneu lo cap de vostre rey, que lo cors resta a la muller e filles! [...]».

Axí lançà lo cap de aquell rey que, ab justa suavitat, com a pare dels pobles, benignament trempava les regnes de sos regnes, egualment amat de sos fills he vassalls (pp. 141-142).

L'autor sembla basar-se en el primer acte de les Troades, on la reina de Troia diu:

Yo, llassa Èucuba, viu un cruel crim, de la mort del rey, e viu molt major crueltat comesa sobre l'altar del temple ab les armes de Axil·les, car viu que Pyrrus, ffer e cruel, hom inhumà, pres lo rey Príam per los cabells et, com los se ach entrellacats en la mà dura e inmisericordiosa, amagà la espasa en la nafra del coll real; e com lo dit rey hagués rebut volenterosament lo fferre dins la sua guola, tragué Pirro la espasa de la nafra tota untada de la sanch del prom, rey vell, antich ${ }^{27}$.

${ }^{27}$ Sèneca, op. cit., II, 341. 
Els dos textos coincideixen, particularment, en el detallisme minuciós del degollament del vell rei Príam per part de Pirros amb la seua espasa, mentre el subjecta pels cabells. Tanmateix, l'autor valencià va molt més enllà des del punt $\mathrm{i}$ hora que remata el degollament inicial amb una decapitació total («acabà tallar aquella part poqua que del primer colp restava» i la víctima «caigué sens cap, com a tronch envellit»). Aquest detall no és baladí, ja que possibilita un segon moment morbós quan Pirros mostra i llança el cap del rei als troians. Al motiu de la decapitació, procedent dels Commentarii in Vergilli Aeneida de Servi ${ }^{28}$, es fa referència brevíssima tant en el Mitògraf Vatica I (213) - «Tunc ejus caput [...] circumtulit» $2^{29} \mathrm{i}$ en les Genealogiae deorum gentilium (VI, 14), on llegim:

unos dicen que fue hecho prisionero por Pirro en su palacio real y fue arrastrado hasta la tumba de Aquiles y allí fue atravesado, se separó su cabeza del cuerpo y fue colocada y paseada en una pica. Otros dicen que junto al altar de Júpiter $[\ldots]^{30}$

La manera en què l'autor valencià ens presenta la mort de Príam se separa força de la que llegim en el passatge corresponent de les Històries troianes, molt més asèptica i bastant alleugerida de detalls morbosos:

E com Pirro fo entrat en lo temple de Apollo, on lo Rey Priam esperaua la mort, contra ell se lexa anar ab la spasa nua, e [presents los maluats Anthenor e Eneas quil guiauen] ocis cruelment lo Rey Priam dauant laltar, e de molt escampament de la sua sanch la maior part del altar fo banyada. ${ }^{31}$

I, per suposat, res té a veure amb la minsa referència que se'n fa en les Metamorfosis (XIII, 404): «Troia simul Priamusque cadunt» [«Troia i Príam cauen al mateix temps»] $]^{32}$.

\section{d) La súplica d'Hècuba a Pirros perquè la mate}

Després de la mort del seu marit, Hècuba es plany davant Pirros i li prega que acabe també amb ella:

$\mathrm{O}$, mare semblant a ovella que fecunda has parit los fills per ser trocejats, partits en diversses parts, roceguats a l'entorn de la tua

${ }^{28}$ Servii Grammatici qui feruntur in Vergilii Carmina Commentarii, cit., II, p. 506.

${ }^{29}$ Apud Josep Lluís Martos, Fonts i seqüència..., cit., p. 222.

${ }^{30}$ Boccaccio, Genealogía..., cit., p. 382. En el llibre XII, cap. 53 de la mateixa obra, també s'al-ludeix breument i sense més detalls al fet que Pirros matà Príam.

${ }^{31}$ Històries, cit., p. 306.

${ }^{32}$ Ovidi, Metamorfosis, cit., III, p. 60. 
ciutat, com aradres fent solchs de gran profunditat en la sangonosa terra! (p. 143)

O, fèbrida spasa de Achilles, guasta e oscada sovint tallant real carn en lo meu miserable ventre criada, y axí muça hi envellida en trossejar los ossos e carn dels fills, que envides ha pogut tallar lo dèbil coll del pare! Fir sens tarda! Squinza e talla les nostres carns femenils e molles, perquè les ànimes prestament fugen de habitatió derrohida! (p. 143)

Es tracta, molt probablement, d'un passatge original de Corella que no sembla tenir succedanis en cap dels models i fonts relacionables amb el Plant.

\section{e) La profecia de Cassandra}

D'acord amb la tradició, la fi de Troia i els consegüents horrors havien estat profetitzats per la sibil·la Cassandra, filla d'Hècuba i de Príam. Les Troades se'n fan ressò en una al·lusió sincopada que apareix en el primer acte, quan la reina diu: «yo Ècuba, com ffuy prenys, viu en sompni tot lo mal que m'és esdevengut e viu tot quant Cassandra, ffuriosa, proffetisà aprés, de la destrucció de aquella ${ }^{33}$. Tanmateix, Roís de Corella reformula aquest motiu i el situa entre la mort de Príam i la de Políxena, de manera que el que era primigèniament una profecia esdevé més bé una constatació de la realitat present que la pròpia Cassandra sembla contemplar. Però, sobretot, l'autor farceix la intervenció de la sibil·la d'un munt d'elements morbosos que la doten d'un patetisme singular:

Los famolents ozells de Grècia a péixer les nostres carns vénen e, als grechs guardant, no toquen, a mescla dels quals, ab rabiosa fam, los troyans cruelment dilacerant squincen. $\mathrm{E}$ los fochs cremants les pedres de Troya sens lesió passar deixen los cobditiosos enemichs per a pendre aquelles riquees que de les grans flames restaurar se poden. Los pochs infants, a cativa servitut no abtes, dels braços de les mares al foch los envien, semblant als de infern, ab tot que demèrits no tinguen encara en aquest món. Dins los petits cremants corsos les ànimes bollir costrenyen $\mathrm{e}, \mathrm{ab}$ gran cuyta, reyal sepultura $\cdot 1 \mathrm{~s}$ donen, que no abans los sperits sens culpa exalen, que llurs carns tendres e molles, ensemps ab los ossors, en vertadera cendra se transporten $[\ldots]$ (p. 145).

\section{f) La mort de Políxena}

La fi d'aquesta filla d'Hècuba i de Príam, a la qual mata també Pirros, malgrat ser tractada d'una manera més sintètica que la del seu pare Príam i la del seu nebot Astíanax, no deixa de prescindir dels

${ }^{33}$ Sèneca, op. cit., II, p. 340. 
trets propis de la intensificació patètica i del detallisme morbós. Hècuba, uns instants abans de ser executada la seua filla, qualifica Pirros de «trosejador de humana carn», ensems que, dirigint-se a Políxena, li diu: «les venes del vostre coll [romanguen] ubertes [...i] abeuren lo sedejant sepulcre de Achiles [...]» (p. 146). Al seu torn, en el moment culminant d'aquest nucli, el degollament de Políxena sobre la sepultura d'Aquil·les, se'ns narra així: «Al mortal colp allargà lo coll la sforçada donzella e, ab la sua verge sanch abundosament regant, abeurà lo desecat sepulcre del fill de Peleu» (p. 148). En aquest cas l'autor, al contrari del que sol ser habitual, sintetitza les fonts de què se serveix.

Entre aquestes, és en les Metamorfosis (XIII, vv. 439-473) on es fa un tractament més extens i detallat:

Rapta sinu matris, quam iam prope sola fouebat;

Fortis et infelix et plus quam femina virgo

Ducitur ad tumulum diroque fit hostia busto.

[...]

Vtque Neoptolemum stantem ferrumque tenentem

$[\ldots]$

'Vtere iamdudum generoso sanguine'; dixit

[...] 'aut tu iugulo uel pectore telum

Conde meo'; iugulumque simul pectusque retexit.

[...]

[...] ipse etiam flens inuitusque sacerdos

Praebita coniecto rupit praecordia ferro.

[«arrenquen als braços de sa mare la que ara gairebé sola la voltava d'afecte; valenta i desventurada, i més que dona, la donzella és conduïda al sepulcre [d'Aquil·les] i esdevé víctima sobre la sinistra tomba. [...] quan veu Neoptòlem que es dreça amb el ferro a la mà $[\ldots]$ «fes rajar tot seguit una generosa sang» diu «[...] o al meu coll o al meu pit enfonsa la teva arma» $\mathrm{i}$ es descobreix alhora el coll $\mathrm{i}$ el pit. [...] el sacerdot, plorant ell mateix i a desgrat seu, li trenca el pit que s'ofereix enfonsant-hi el ferro»] $]^{34}$.

Tot el contrari del que trobem en les Troades, on la mort de Políxena, d'acord amb les pautes de la tragèdia clàssica d'ometre la visualització de tot el que es considerava obscé -etimològicament 'allò que no es pot representar en escena pel seu caràcter morbós'- és només al·ludida però no representada. Així, en l'acte 3r, el grec Agamèmnon recrimina a Pirros la seua intenció que «Políxena, donzella bella, verge graciosa, ffilla del rey Príam, sia degollada e sia morta

${ }^{34}$ Ovidi, Metamorfosis, cit., III, pp. 61-62. 
sobre lo sepulcre de Axil-les e que ab la sua sanch banye e regue lo dit sepulcre» ${ }^{35}$, mentre que, en l'acte $5 e ́$, es plany Hècuba:

O Pirro!, e per què trigues? E per què çesses exercir la tua crueltat? Ffes, amaga la tua espasa dins les entràmenes de Políxena [...]. [...] Aquesta sang de Políxena pertany a tu, aquesta deu ésser per tu escampada. Ay lassa, que Políxena deu ésser arrapada e presa de la falda de la sua mare e és portada al loch on deu morir ${ }^{36}$.

Per una vegada, Roís de Corella, s'acosta més al model menys grandiloqüent de les Històries troianes. Aquesta obra, malgrat caracteritzar-se pel predomini d'un discurs narratiu generalment sobri i molt poc procliu als excessos efectistes, quan ens presenta la mort de Políxena, supera en aquests aspectes el tractament que en fa l'autor valencià, ja que no sols relata el degollament d'aquesta, sinó que hi afegeix el detall de l'esquarterament posterior del seu cos:

E com aquestas coses Polixena deya, Pirro ab la espasa, dauant lo sepulcre de son pare, cruelment la ocis, veent ho Hecuba, sa mara; e lo seu cors, per peçes troceiat, rega lo moniment del pare en molta habundancia de la sanch virginal ${ }^{37}$.

No obstant, Joan Roís de Corella mai no arriba a l'asèpsia de manual pròpia de les Genealogiae deorum gentilium, on la mort de Políxena és al·ludida de manera gens ni mica emfàtica: «el truculento joven la condujo [...] hasta la tumba de Aquiles y la mató ${ }^{38}$; o «mató a Políxena, docella de notable belleza, junto al sepulcro de Aquiles $»^{39}$.

\section{g) La mort d'Astianax}

L'última seqüència del Plant adduïble al nostre propòsit és la de la mort d'Astíanax -fill petit d'Hèctor i Andròmaca i, per tant, nét d'Hècuba i Príam- a mans d'Ulisses. A diferència del que s'esdevé en la pràctica totalitat de les diverses obres que recullen aquest motiu -les Metamorfosis, les Troades, les Històries troianes, l'Ovide moralisé o l'Ovide moralisé en prose-, en què la mort del xiquet es produeix abans de la de la seua tia Políxena, Roís de Corella la situa després de la d'aquesta com a cloenda del Plant. Josep Lluís Martos $^{40}$ ha fet notar que només les Genealogiae deorum gentilium coincideixen amb Corella a situar la mort d'Astíanax després de la

\footnotetext{
${ }^{35}$ Sèneca, op. cit., II, p. 352.

${ }^{36}$ Ibid., II, p. 385.

${ }^{37}$ Històries, cit., p. 310.

${ }^{38}$ Boccaccio, op. cit., p. 385 (VI, 21).

${ }^{39}$ Ibid., p. 714 (XII, 53).

${ }^{40} \mathrm{Cfr}$. el seu article «Boccaccio y Joan Roís de Corella...», cit., p. 224.
} 
de Políxena. Tanmateix, crec que aquest fet no permet deduir una dependència de l'autor italià per part del valencià, sinó que es tracta d'una coincidència fortuïta a partir de causes diferents en cadascun dels dos escriptors. En efecte, si al llibre VI del manual mitogràfic de Boccaccio les morts de Príam, Políxena i Astíanax són recollides, respectivament, en els capítols 14,21 i 25 , és perquè aquest manual segueix un orde genealògic en l'exposició de tots els mites. En l'autor valencià, però, el fet de desplaçar la mort d'Astíanax al final, dins d'un text argumentalment compacte com és el Plant, tan diferent de les Genealogiae, respon a un propòsit estètic d'intensificació patètica i d'efectisme melodramàtic. Aquest és el motiu, i no altre, pel qual, en el Plant s'estableix una gradació generacional en els ajusticiaments de tres representants destacats de la dinastia troiana: primer, el rei Príam; en segon lloc, la seua filla Políxena, i, finalment, el seu nét Astíanax.

Precisament, és, una vegada més, la consecució de l'efectisme suara esmentat el que porta Roís de Corella a amplificar amb detalls morbosos el relat de la mort del nét de Príam en relació als models literaris que tenia al seu abast. Així, en el text corellà, diu Ulisses a la mare del xiquet al temps que li'l lleva dels braços per a tirar-lo des d'una torre:

Aparta't, mare trista, no veges ton fill rodar en l'ayre lançat de aquella alta torre que sola sens cremar resta, la qual de les flames per alre no més feta delliure, sinó perquè, d'ella en lo més alt, lo fill de Ėctor, empés, en diversos e chichs trosos lo seu cors partit, sia imposible als qui diligentment lo plegaran, les sues parts en ell mort tinguen lo loch que vivint tenien (p. 149).

I, tot seguit, ens informa Hècuba:

Axí anava lo sforçat infant a la desijada mort, deixant la trista mare, la cara guardant los cels, stesa en la dura terra, semblant a vertadera morta, la boqua de la qual, ja freda, piadosament besant, pres per la mà a Ulixes en semblança que ell a mort lo portàs.

Los ayres scurits retronaven, lo sol de color de sanch se vestia, la terra murmurant en amples cavernes obrint reclamava e tot l'univerç per strem dol general decahiment en breu prometia, e la cara del fill de Èctor no's mudava. Ab dolorosos ciscles que'n los darrers cels clarament se hoyen, tots ploraven sinó aquell sol per qui tots ploren (p. 150).

Després de ser precipitat Astíanax per Ulisses des de la torre, conclou Hècuba el seu sentit Plant confessant que, malgrat que moltes vegades ha intentat narrar per escrit el tràgic desenllaç del seu nét, 
mai no ho ha aconseguit, perquè el paper en què ho havia de fer no ha consentit que s'hi escriguera aquest fet cruel:

Ans la tinta negra, començant escriure lo caure de la tan alta torre, convertint-se en habundosa sanch, axí lo blanch paper tenyint abeurava, que m'era forçat deixar-me de tan dolorosa scriptura. Que en altres cartes la mort de aquest fill de l'animós Èctor no consent ésser scrita, sinó en les dures roques, sobre les quals cahent, lo seu delicat cors partit, trosejat e dilacerat, de real sanch ha tintes [...] (p. 150).

Ni l'al·lusió d'Ulisses a l'esquarterament del cos de Astíanax en petits fragments després de ser llançat des de la torre, cosa que impossibilitarà reconstruir el cadàver, ni la serenitat de l'infant en els moments previs a la seua mort, ni l'esmortiment de la mare quan aquest la besa en el comiat final, ni el «cataclisme còsmic»» ${ }^{41}$ que es produeix en el moment de l'execució, ni la hipèrbole de la inefabilitat del dolor que es posa en boca d'Hècuba com a conclusió de l'obra no es poden documentar en els models principals del passatge.

Les Metamorfosis (XIII, vv. 415-417) es limiten a constatar molt sinòpticament:

Mittitur Astyanax illis de turribus, unde

Pugnantem pro se proauitaque regna tuentem

Saepe uidere patrem monstratum a matre solebat.

[«Astíanax és llançat daltabaix d'aquelles torres des d'on sovint solia veure el seu pare, que la seva mare li mostrava lluitant per ell i defensant el regne dels seus avantpassats». $\left.{ }^{42}\right]$

Les Troades tampoc són gaire més explícites en les tres breus seqüències de l'acte $4 \mathrm{t}$ que s'hi poden posar en relació. En la primera d'aquestes, exclama Andròmaca: «O mare trista! ¿e poràs tu mirar lo teu ffill qui serà liurat a mort cruel? ¿Poràs-lo veure com lo gitaran de una torre molt alta e caurà rodant, adés lo cap avall, adés amont? $\gg^{43}$. En la segona, Astíanax, adreçant-se a la seua mare, manifesta un realista sentiment de por que res no té a veure amb la increible serenitat que li atribueix Roís de Corella: «Ay mare mia, hages mercè de mi!» ${ }^{44}$. Finalment, en la tercera seqüència, Ulisses diu a Andròmaca: «Null temps haurà ffi aquest plor», ensems que ordena: «Vosaltres, escudés meus, espaxats-vos e prenets aquest fill de

${ }^{41}$ Sobre aquest concepte, vid. Josep Lluís Martos, «El cataclisme còsmic en l’obra de Joan Roís de Corella», dins Jesús Cañas Murillo, Francisco Javier Grande Quejigo i José Roso Díaz (eds.), Medievalismo en Extremadura. Estudios sobre literatura y cultura hispánicas de la Edad Media, Cáceres, Universidad de Extremadura, 2009, pp. 835-845.

${ }^{42}$ Ovidi, Metamorfosis, cit., III, p. 60.

${ }^{43}$ Sèneca, op . cit., II, 370.

${ }^{44}$ Ibid., II, 376. 
Andròmaca $[\ldots]\rangle^{45}$. I no cal dir que, com en el cas de Políxena, l'execució material del crim s'omet per tractar-se te d'un element obscé en la tradició teatral clàssica. Al seu torn, la informació d'aquesta mort en les Genealogiae (VI, 25) es manté dins la línia habitualment asèptica d'aquest manual mitogràfic, absolutament allunyada de l'estètica corellana: «fue arrojado desde la torre, según sostienen algunos, o estrellado contra las rocas, según otros, y así fue muerto para que no hubiera ninguna descendencia libre del linaje de Príamo» ${ }^{46}$. I, per concloure, només resta assenyalar que en les Històries troianes (llibre XXX) s'omet totalment la mort d'Astíanax ${ }^{47}$.

\section{MEDEA A LES DONES}

Roís de Corella recrea el mite de Medea mitjançant una lletra d'aquesta adreçada genèricament a les dones, en la qual, amb el to elegíac propi de les Heroides ovidianes ${ }^{48}$ els relata en primera persona la seua dissortada història d'amor amb Jàson, qui acaba rebutjant-la per una altra dona. La lletra de Medea, impregnada d'un marcat accent filogin ${ }^{49}$, és, en aquest cas, un instrument admonitori per a prevenir les dones dels enganys dels homes.

L'obra consta de dues parts. La primera, tributària dels llibres II i III de les Històries troianes ${ }^{50}$, desenvolupa el tema de l'expedició de Jàson i dels argonautes a la recerca del velló d'or a l'illa de Colcos, de la qual és rei Eet, pare de Medea. Aquesta s'enamora de Jàson, l'ajuda en la seua comesa i acaba unint-se a ell. La segona part, deutora fonamentalment de la Medea de Sèneca, ${ }^{51}$ tracta de la infidelitat de Jàson -qui repudia la seua dona per a casar-se amb Creüsa, filla del rei de Corint- i de la venjança de Medea, la qual bota foc al palau reial corinti i mata els seus propis fills haguts amb Jàson. Aquest

${ }^{45}$ Ibid., II, 377.

${ }^{46}$ Boccaccio, op. cit., p. 390.

${ }^{47}$ Op. cit., pp. 299-311.

${ }^{48}$ No debades la lletra XII de les Heroides (ed. i trad. catalana d'Adela M. Trepat i Anna M. de Saavedra, Barcelona, Fundació Bernat Metge, 1927), que Medea escriu a Jàson, també es fa ressò del tema, si bé al·ludeix a una situació posterior a la infidelitat d'aquest però anterior a la venjança d'aquella; per tant no es pot considerar com a font bàsica de Roís de Corella.

${ }^{49}$ Vid. Rosanna Cantavella, «Sobre el Triunfo de les dones de Roís de Corella», dins José Manuel Lucía Megías i Paloma Gracia (eds.), Actas del II Congreso Internacional de la Asociación Hispánica de Literatura Medieval (5-9 octubre 1987), Alcalá de Henares, Universidad de Alcalá de Henares, 1992, II, pp. 217-228; Antònia Carré, «L'Espill de Jaume Roig i El triunfo de les dones de Joan Roís de Corella», A sol post. Estudis de llengua i literatura, 3 (1995), pp. 91-94, i Tomàs Martínez Romero, «Per a una interpretació del Triümfo de les dones, de Roís de Corella: claus ecdòtiques i literàries», Estudis de Llengua i Literatura Catalanes, 33 (=Miscel-lània Germà Colón, 6), Barcelona, Publicacions de l'Abadia de Montserrat, 1996, pp. 37-69.

${ }^{50}$ Ed. cit., pp. $15-46$.

${ }^{51} \mathrm{Amb}$ alguns elements provinents de les Metamorfosis (VII, 1-424) (cfr. Cingolani, op. cit., p. 140). 
mite es troba recollit també, entre altres textos, en les Genealogiae de Boccaccio (IV, 12; XIII, 26).

Per al que ens interessa en aquest article, seleccionarem dues seqüències de la segona part de l'obra que poden resultar altament il. lustratives: la que recull el moment en què Medea decideix fugir-se'n amb Jàson, i la corresponent a la venjança d'aquesta per la infidelitat del seu estimat.

\section{a) La fugida de Medea amb Jàson}

Medea, seduïda per Jàson, decideix fugir-se'n amb ell i donar-li els tresors del seu pare; però, a més, explica la protagonista:

La temor que de perdre Jàson tenia, me féu portar amb mi un infant, germà meu, lo qual, ab més pròpies mans degollant, partí e dilacerí lo seu chich, moll e tendre cors en parts diverses, sembrades en la polsosa terra, perquè mon pare, perseguint Jàson per cobrar a mi e los seus tresors, fos axí torbat en cobrar e collir los troços e membres de son fill, escampats en la sangonosa terra, que a mi restàs spay de fogir ab lo meu Jàson (p. 230).

Si anem a la font que sembla haver inspirat principalment la segona part d'aquesta obra corellana, la Medea de Sèneca, no hi trobem cap correlat estricte d'aquest fet, ja que l'acció comença posteriorment, quan Jàson ja està casat amb Creüsa. Tanmateix, sí que s'hi fa una al·lusió clara a l'execució dels dos fills que havia tingut amb Jàson, en els moments previs a la materialització de la seua venjança:

[...] dos n'é parits, hi assats per satisfer a la mort de mon frare, lo qual per amor de Jàson matí, e la dolor de mon pare, lo qual, matant mon ffrare, acorís ${ }^{\prime 2}$.

E quina ombra és aquesta que veja venir, de una persona morta la qual se acosta vers mi dubtosa e ja tota apar pecejada e desvibronada en sos membres del cors? Sens dubte, aquest és lo meu frare. Vanjanca deman, e obtenrré-la, car nós ho sostendrem ${ }^{53}$.

Si bé és cert que en Sèneca el crim de Medea afegeix la dimensió, absent en Corella, de venjar el germà que va matar per facilitar-se la fugida amb Jàson, el que ens interessa destacar és que la referència al detall morbós de l'esquarterament de l'infant en diverses parts també es troba en la citació senequiana, per bé que d'una manera menys emfàtica i més sinòptica, ja que prescindeix de l'al·lusió final a la tasca d'arreplega, per part de l'avi, dels fragments del cos del seu nét

\footnotetext{
${ }^{52}$ Sèneca, op. cit., II, p. 446

${ }^{53}$ Ibid., II, p. 446.
} 
escampats per tot arreu. La descripció més freda del fet és, com sol ser habitual, la de les Genealogiae (IV, 12):

Puesto que Etes los perseguía, para que se les procurara una distancia en su huída, [...] degolló al niño Apsirto [el seu germà] y despedazado en trozos lo arrojó en todas direcciones a lo largo de los campos, de manera que detuviera a su padre para reunir los miembros del hijo ${ }^{54}$.

\section{b) La venjança de Medea}

Després d'haver botat foc al palau de Creont mitjançant arts malèfiques ${ }^{55}$ tot provocant la mort del rei i de Creüsa, la Medea de Roís de Corella - no la de Sèneca- anuncia a Jàson el que esdevindrà el fet culminant de la seua venjança, amb la qual cosa s'aconsegueix subratllar l'ingredient morbós, incrementat encara més, si cap, per l'al·lusió al mite de Tereu -en què ens detindrem més endavant-, amb el qual el que ara ens ocupa té paral·lelismes evidents:

No $t$ recordaves que de tu tenia fills, los quals, ans que d'ací $t$ perteixques, en la tua presència degollaré. Fent troços de llurs tendres carns e molles, comportaré que·ls dónes tu sepultura. E no $\cdot m$ desplau sinó que sobergua ira tan fort me turmenta, que no m'à comportat hun poch spay haja tardat pendre de tu acabada venja, semblant a la de Prognes e Filomena: donant-te a menjar tos fills, perquè engendrats de tal pare, dins les tues perverses entramenes tinguesen, aprés lur mort, convinent sepulcre (p. 234).

Tot seguit, narra Medea:

tallí lo cap dels fills de Jàson, tirant-los a la cara del pare, ab lo coltell, que de la corrent sanch tint restava, dient:

«Dóna sepultura a tos fills, puix les tues desconeixences no·ls han comportat més viure. Aprés, ab lo coltell sangonós travesant, squinça lo teu cors pervers, abominable, perquè en los inferns la miserable ànima inefable pena soporte» (p. 236).

En l'escena homòloga de la tragèdia de Sèneca, en la qual l'autor valencià s'inspira, Medea s'adreça a l'espectre del petit germà a qui havia donat mort $\mathrm{i}$ esquarterat per amor a Jàson amb aquest termes:

\footnotetext{
${ }^{54}$ Boccaccio, op. cit., pp. 238-239.

${ }^{55}$ En Corella, com en les Genealogiae (IV, 12, i XIII, 64; veg. Boccaccio, op. cit., pp. 239 i 784-785, respectivament), Medea envia els seus fills a Creüsa amb una capseta que simula ser un obsequi de reconciliació i, quan la destinatària l'obri, es produeix l'incendi. En la major part dels textos que documenten aquest motiu, però, el regal amb propietats malèfiques és una camisa o peça de vestir, tal com ha assenyalat Martos («Boccaccio y Joan Roís de Corella: las Genealogiae deorum», cit., p. 210).
} 
Leixa, frare meu, a mi la pena sola, e serveix-te de aquesta mia mà, la qual estrengué molt ffermament la spasa com yo, per amor de Jàson, trocegí a tu. Per què davant tu mateix degolle aquest meu fill, de Jàson e meu, per ffer sacriffici als teus déus e per mitigar-los.

$\mathrm{O}$ mi, Medea, quin so, quin brogit és aquest? E jo veig que grans armes se aparellen e cerquen-me per matar-me. Pujar-me-n'he en lo sobiran terrat de la mia casa per deffensar-me. E pus he comencat $\mathrm{e}$ mort la hun, resta que acabe la obra, que mate l'altre. Adonchs, ffill meu, segueix-me, vine a mi, aporta lo teu cors ací, a mi.

E tu, Medea, prossegueix açò que as comencat. No perdes la virtut ni la ffama mattant-lo amagadament: mata'l davant tot lo poble, pus que ací, en l'altitut del terrat, te veu tot lo món. Crida, donchs, tothom que vegen la mort de ton fill ${ }^{56}$.

Si establim una comparació entre els dos textos suara esmentats, observem que, malgrat el major grau de desenvolupament de l'escena en la tragèdia de Sèneca -els assassinats dels dos fills es produeixen en espais i temps diferents, $i$ el del segon a la vista de tot el poble-, la visualització del crim és més viva i efectista en l'obra de Roís de Corella, ja que s'hi explicita una decapitació en presència de Jàson, al qual són llançats els caps de les criatures. Així mateix, la venjança, en el cas de l'autor valencià, es produeix com a resposta a la infidelitat de Jàson, mentre que en Sèneca, a més d'això, es vincula també al fet específic de l'infanticidi del germà de Medea per part d'aquesta per les raons que ja coneixem. En qualsevol cas, la connexió amb el desenllaç de la tragèdia senequiana és molt major que amb l'extremadament succint $\mathrm{i}$ carent de detalls que presenta aquest mite en les Genealogiae (IV, 12):

Pero como Jasón, irritado contra ella hubiese corrido a castigar un crimen tan impío [l'incendi del palau de Creüsa amb ella dins], la terrible mujer mató antes sus ojos a sus inocentes hijos $[\ldots]^{57}$.

\section{LA HISTÒRIA DE PASÍFAE}

Es tracta d'un dels cinc mites constitutius del Parlament en casa de Berenguer Mercader. Roís de Corella el posa en boca de Lluís de Castellví i està inspirat en l'Ars amandi d'Ovidi (I, vv. 289-330 ${ }^{58}$.

Pasífae, muller del rei Minos, en absència d'aquest, s'entreté passejant pel camp i gaudint de la contemplació de la diversitat vegetal i animal. És llavors quan s'enamora d'un bell toro blanc, tan

\footnotetext{
${ }^{56}$ Sèneca, op. cit., II, p. 447.

${ }^{57}$ Boccaccio, op. cit., p. 239.

${ }^{58}$ Publi Ovidi Nasó, Art amatòria, ed. i trad. catalane de Jordi Pérez i Durà, amb la col·laboració de Miquel Dolç, Barcelona, Fundació Bernat Metge, 1977.
} 
apassionadament i malaltissament que arriba a desitjar ocupar el lloc de la vaca companyona d'aquest toro ${ }^{59}$ a qui enveja sense remei:

$\mathrm{E}$ ab més atenció de la gran bèstia mirant la bella forma, començà collir de amor desonesta -o, infernal fúria!- les primeres purnes, stimant gran benaventura la vaqua, muller de tal marit, possehia. E, dins si pensant, rahonava:

«O! Si a mi era posible, semblant a la mare de Achilles, en diversitat de formes mudar la figura, no.m desdenyaria amar tan mansueta bèstia. Mas, si ara yo l'ame, a quina fi mon voler acabaria, si ell no conex la humana bellea?»

$\mathrm{O}$, maldat desonesta, passant totes les altres! Desigava la rational ànima perdre, perquè, tenint de brut animal la forma, la legea de tant desorde pogués venir a miserable terme.

Pogué tant la infernal enamorada fúria de la desonesta reyna, que, de reyals riques vestidures cuberta, assajà si a l'amat thoro als tàlems de la sua castedat entraria. Mas lo cast discret animal, no passant los límits de la conditió acostumada, a son rey e senyor fidelíssim vassall e servent, girant la cara, tornà atràs, quant veu de la desonesta reyna la persona descuberta, abominant entrar en les claustres de la castedat de la sua senyora. Ja tenia vergonya la desvergonyida reyna de veure lo fel thoro retraure's de cometre legea de tant delicat delicte e vil acte. Però, a tant no bastà que, ab infuriada pensa, dexàs cerquar qualsevol art ab què lo seu nephandíssim voler atengués al desigat terme. E, a la fi, ab l'artifici de Dédalus, ${ }^{60}$ qui en aquella edat en mecànica art los vivents tots excellia, ella, abominable, féu en fusta sculpir una vaqua ab pell de la muller del thoro cuberta, dins la qual, en acte desonests enganant la ignocent bèstia, concebé lo monstruós animal, Minotaur, de qui la fama, en vergonya de la femenil condició, eternament dura (pp. 267-268).

L'escriptor valencià resumeix amb prou fidelitat la font ovidiana, però, quan arriba al punt culminant de la història, l'aparellament de Pasífae amb el toro, es recrea amb tot luxe de detalls morbosos en l'explicació de com aconsegueix que l'animal la deixe prenyada: l'enganya fent-se passar per la seua parella bovina, la qual ordena matar per recobrir amb la seua pell un artefacte de fusta construit $a d$

${ }^{59}$ Com precisa Martos («Boccaccio y Joan Roís de Corella: las Genealogiae deorum», cit., p. 170), que la vaca siga la muller del toro no és enlloc; només en Servi (op. cit., VI, 24) es diu que n'era la vaca predilecta.

${ }^{60}$ Joan Roís de Corella pot haver pres el motiu de la col·laboració de Dèdal, absent en Ovidi, de les Genealogiae (IV, 10; Boccaccio, op. cit., p. 239), on es resumeix el mite de Pasífae així: «Fue esposa de Minos, rey de Creta, y al estar ausente Minos en guerra contra Megarenses y Atenienses por el asesinato de su hijo Andrógeo [...], sintió las llamas de un amor funesto y amó a un toro de hermosísima apariencia, a cuya unión se dice que llegó gracias al artificio de Dédalo y de él concibió al que dio luz medio hombre y medio toro» (Boccaccio, op. cit., pp. 235-236). 
hoc per a ocultar-se dins i copular amb la bèstia, fent-li creure que és la seua vaca. Aquesta explicació contrasta amb la concisió del desenllaç ovidià: «hanc tamen impleuit vacca deceptus acerna/ dux gregis, et partu proditus auctor erat» (vv. 325-326) [«Mentrestant el cap de l'arment la prenyà, enganyat per la imatge d'una vaca d'auró, i amb l'infantament om descobrí qui era el pare»] ${ }^{61}$. Té raó Martos ${ }^{62}$, doncs, quan afirma que «Corella [...] se centra en el punt àlgid del mite, en l'aparellament d'ambdós», amb l'escabrositat que aquest fet comporta.

\section{La història de Tereu, Procne i Filomela}

En aquesta faula es relata un cas pervers d'infidelitat masculina, com en Medea, però, sobretot de violència sexual. Està inspirada, fonamentalment, en les Metamorfosis (VI, vv. 412-674) i en les Genealogiae (IX, 8 i, més sintèticament, XII, 75). Així mateix, presenta certes concomitàncies amb la tragèdia Thyestes de Sèneca ${ }^{63}$.

Tereu, rei de Tràcia, venç Pandíon, rei d'Atenes, qui, una vegada signada la pau, li atorga per muller la seua filla Procne. Després de sis anys a Tràcia, Procne manifesta al seu marit el desig de veure la seua germana Filomela, que havia romàs a Atenes a cura del seu pare. Tereu accedeix a viatjar a Atenes per a dur-li-la, a fi que faça amb ells un sojorn a Tràcia. Després d'aconseguir l'autorització reial corresponent, amb la seua cunyada Filomela, emprén el viatge marítim de retorn a Tràcia. Una vegada allí, abans de presentar-li-la a Procne, la viola i li talla la llengua per assegurar-se el silenci del fet. Tanmateix, la víctima aconsegueix informar-ne la seua germana, la qual, amb la col·laboració de Filomela, es venja de Tereu matant el fill que havia tingut amb ell, i fent-li-lo menjar en un banquet.

En l'obra podem distingir quatre passatges amb components morbosos, que acararem tot seguit amb les seues fonts llatines corresponents: la violació de Filomela, la seua mutilació lingual, la mort del fill de Tereu i Procne a mans d'aquesta i, en últim lloc, l'escena

${ }^{61}$ Publi Ovidi Nasó, Art amatòria, ed. i trad. catalana de Jordi Pérez i Durà, amb la col·laboració de Miquel Dolç, Barcelona, Fundació Bernat Metge, 1977, p. 48. Ovidi hi al·ludeix al fet que Pasífae manà matar la vaca, però sembla més que per gelosia que per a aprofitar-ne la pell per a recobrir l'artefacte de fusta amb què enganya el toro: «et ingenti iamdudum de grege duci/ iussit et inmeritam sub iuga curua trahi,/ aut cadere ante aras commentaque sacra coegit/ et tenuit laeta paelicis exta manu» (vv. 317-320) [«ordenà que fos treta [la vaca] de l'ingent ramat i que la innocent fos arrossegada sota la corba del jou, o bé l'ha feta caure davant dels altars, simulant un sacrifici, i ha tingut a les mans joioses les entranyes de la seva rival»] (Publi Ovidi Nasó, Ars amatòria, cit., p. 48). El motiu de la pell de la vaca sí que es documenta en l'Ovide moralisé i l'Ovidius moralizatus (cfr. Martos, «Boccaccio y Joan Roís de Corella: las Genealogiae deorum», cit., p. 169).

${ }^{62}$ «Boccaccio y Joan Roís de Corella: las Genealogiae deorum», cit., p. 163.

${ }^{63}$ Cfr. Josep Lluís Martos, «Sèneca i Roís de Corella», dins Carmen Parrilla i M. Pampín (eds.), Actas del IX Congreso Internacional de la Asociación Hispánica de Literatura Medieval (A Coruña, 18-22 de septiembre de 2001), Noia, Toxosoutos, 2005, III, pp. 131-150, p. 132. 
d'antropofàgia en què el pare, bé que ignorant-ho, es menja la carn del seu fill i se'n beu la seua sang pensant que és vi.

\section{a) La violació de Filomela \\ És el fet desencadenant de la tragèdia i Roís de Corella el reporta d'aquesta manera:}

Stava prop les ribes un antich palau ${ }^{64}$ lo qual Thereu tenia per aleujar la sollicitud de la real fatigua, ab plaent deport en delitosa casa. Pres per la mà lo inich tirà la fatigada donzella; fengint que li mostrava la antigua posada, portà-la en lo més secret apartament, dient-li paraules al desorde de la sua amor o fúria conformes [...]. A la fi, com a leó famolent, dilacerant les vestidures de la plorant temerosa donzella, $a b$ tan gran força com la sua tendra delicadura resistir podia, entrant en los prats de la casta pudicícia, collí los liris de la sua verginitat honesta (pp. 274-275).

El text depén clarament de les Metamorfosis (VI, vv. 518-527), on l'episodi se'ns presenta així:

Iamque iter effectum iamque in sua litora fessis

Pubbibus exierant, cum rex Pandione natam

In stabula alta trahit siluis obscura uetustis

Atque ibi pallentem trepidamque et cuncta timentem

Et iam cum lacrimis, ubi sit germana, rogantem

Includit fassusque nefas et uirginem et unam

Vi superat frustra clamato saepe parente,

Saepe sorore sua, magnis super omnia diuis.

[Ja havien acabat el viatge, ja arribaven a les costes de la pàtria de les cansades naus, quan el rei arrossega la filla de Pandíon a una recòndita establia, enfosquida per velles boscúries, $i$ allà, pàl·lida $i$ tremolosa $i$ tement-ho tot $i \mathrm{ja}$, amb llàgrimes, demanant on és la germana, la tanca; i havent-li confessat el seu sacríleg designi, per la força la venç, donzella tota sola que en va crida ara el seu pare, ara la germana, $i$ sobretot les grans divinitats ${ }^{65}$.]

Malgrat el gran paral·lelisme existent entre la font i la recreació corellana, s'observen en aquesta última alguns detalls que intensifiquen la violència morbosa de la situació. Així, mentre que en Ovidi Tereu confessa a Filomela «el seu sacríleg designi», en Corella li diu

${ }^{64}$ Ovidi, en les Metamorfosis (VI, 521), parla d'un estable; i Boccaccio, en les Genenealogiae (IX, 8), diu que és la cabanya d'un pastor; l'Ovidi moralisé (VI, vv. 2945-2949) situa l'acció en una casa abandonada que Tereu tenia per al seu oci.

${ }^{65}$ Ovidi, Metamorfosis, cit., II, pp. 18-19. 
paraules «al desorde de la sua amor o fúria conformes». Així mateix, l'autor valencià compara l'actitud de Tereu amb la d'un «lleó famolenc», imatge expressiva absent en Ovidi, el qual, a més a més, sintetitza l'acte estricte de la violació en un «per la força la venç», que Corella amplifica retòricament i d'una manera molt més gràfica $i$ efectista per a fer-nos copsar la intensitat de la violència exercida sobre la donzella: «dilacerant les vestidures de la plorant temerosa donzella, ab tan gran força com la sua tendra delicadura resistir podia, entrant en los prats de la casta pudicícia, collí los liris de la sua verginitat honesta».

\section{b) La mutilació de la llengua de Filomela}

En aquest passatge la dependència d'Ovidi és també molt evident i, a més, no es pot dir que, ací, Roís de Corella haja intensificat gaire els motius morbosos en relació al seu model. Vegem-ho. L'autor valencià descriu l'escena així:

Pensant lo cruel tirà en la legea del que acabava, ab major peccat delliberà si $\cdot 1$ primer cobrir poria, perquè és de costum dels viciosos actes, si ab penediment no se smenen, a majors delictes nos conviden. Pres, donchs, lo ferox animal les blanques mans de la lagrimant donzella e, ligades sobre les espatles, com a carnicer que al mansuet anyel a degollar se aparella, de la bayna tirà la febrida spasa. Sperant la trista cunyada la desigada mort, allarguant lo coll, començà la lengua a moure per dir paraules tals, que major ira li portasen, perquè cuytàs lo colp de la mortal ferida. Mas la iniqua fortuna encara de morir no la volia complaure, perquè acostuma la cruel mort fogir del qui la demanen e, als benaventurats qui la temen, sens alguna mercé asalta. Pres, donchs, ab les desonestes mans l'enemic cunyat la tendra lengua, la qual tallant, lançà a terra. Aquella part que pres havia, stava saltant en la sangonosa terra, cerquant lo loch d'on era tallada (p. 276).

Mentre que, en les Metamorfosis (VI, vv. 549-561), llegim:

Talibus ira feri postquam commota tyranni

Nec minor hac metus est, causa stimulatus utraque,

Quo fuit accinctus, uagina liberat ensem

Arreptamque coma flexis post terga lacertis

Vincla pati cogit; iugulum Philomela parabat

Spemque suae mortis uiso conceperat ense;

Ille indignantem et nomen patris usque uocantem

Luctantemque loqui conprensam forcipe linguam

Abstulit ense fero; radix micat ultima linguae,

Ipsa iacet terraeque tremens inmurmurat atrae,

Vtque salire solet mutilatae cauda colubrae,

Palpitat et moriens dominae uestigia quaerit. 
[Després que amb això s'ha mogut la ira del feroç tirà, i no és més petita que ella la seva por, agullonat per l'una i l'altra causa allibera de la beina l'espasa que portava cenyida i, aferrant-la per la cabellera, torçant-li darrera l'esquena els braços, la força a sofrir lligams. Parava Filomela el coll i, en veure l'espasa, havia concebut l'esperança de la pròpia mort; ell, però mentre la seva llengua indignada cridava encara el nom del pare i lluitava per parlar, agafant-la-hi amb tenalles, la talla amb la seva espasa feroç; salta l'arrel última de la llengua, la llengua mateixa jeu trèmula i murmura sobre la terra negra; i, com sol frisar la cua d'una mutilada serp, palpita i cerca en morir els vestigis de la seva posseïdora ${ }^{66}$.]

Tots dos textos coincideixen en una sèrie de motius: el temor de Tereu davant la possibilitat que la víctima revele la violació i la decisió de tallar-li la llengua amb l'espasa perquè res no puga dir; el lligament de les mans a l'esquena per a subjectar-la; el de facilitar la disposició del coll, per part de Filomela, tot esperant que el seu boxí la degolle i acabe definitivament amb ella; el de l'execució concreta de la mutilació de l'òrgan, i, en fi, el dels moviments autònoms d'aquest després de tallat. Sembla, doncs, que en aquesta ocasió, el text de l'escriptor valencià no afegeix més trets morbosos dels que li subministra la font ovidiana que segueix, però, sí que és possible trobar-hi alguns elements intensificadors de la morbositat pròpia de la seua opció estètica, com ara l'antítesi continguda en la frase «Pres, donchs, lo ferox animal les blanques mans de la lagrimant donzella», i la intensificació retòrica del final, quan es refereix al fet que la llengua mutilada «stava saltant en la sangonosa terra, cerquant lo loch d'on era tallada».

\section{c) La venjança de Procne}

Tot i que Tereu ha tingut bona cura d'ocultar a la seua muller Procne la violació i mutilació de Filomela, fent-li creure que aquesta ha mort durant el trajecte marítim cap a Tràcia, la víctima aconsegueix assabentar dels fets a la seua germana mitjançant un recurs enginyós: li envia una peça de tela amb un missatge brodat en lletres gregues -incomprensibles per als intermediaris que li l'han de fer arribar a la destinatària- en el qual explica la seua dissortada història. Procne, d'amagat, va a buscar-la i la porta al palau, a l'hora que planeja venjar-se del seu marit matant, amb la col-laboració de Filomela, el fill que havia tingut amb ell i donant-li-lo a menjar. Heus ací el relat macabre de l'infanticidi:

pres per los daurats cabells lo miserable príncep, lo qual, plorant, solament recelava mal de acostumat castich de piadosa mare. E, ab

${ }^{66}$ Ovidi, Metamorfosis, cit., II, p. 20. 
la fèbrida spasa del pare, ferí de cruel colp lo tendre coll del fill, ajudant-hi la injuriada tia. E, multiplicant en mortals ferides, lo chic infant en sangonosos troços squinçaren. A la una part, encara mig vius, en les bollints olles donaren inquieta sepultura: los altres, $a b$ asts aguts travesats, als grans fochs acostaven. O, cosa de admiratió excelsa! Que les cremants flames, fogint, temien rostir innocent carn humana. E la mare e la tia, grans tronchs ajustant, treballaven acabar de bé coure la miserable vianda (p. 280).

És evident que també ara Roís de Corella segueix molt de prop el relat de les Metamorfosis (VI, vv. 640-646), el qual, de la mateixa manera que la prosa de l'autor valencià, es fa ressò del pànic de l'infant i de la seua immediata execució per la seua mare i la seua tia, les quals, després d'infligir-li múltiples colps d'espasa, el degollen i l'esquarteren:

[...] et iam sua fata uidentem

Et 'mater, mater' clamantem et colla patentem

Ense ferit Procne, lateri qua pectus adhaeret,

Nec uultum uertit; satis illi ad fata uel unum

Vulnus erat, iugulum ferro Philomela resoluit;

Viatque adhuc animaeque aliquid retinentia membra

Dilaniant; pars inde cauis exultat aenis,

Pars ueribus stridunt; manant penetralia tabo.

[...ja veia el seu destí i cridava: «Mare! mare» tirant-se-li al coll, amb una espasa el fereix Procne, allà on el pit s'agafa al flanc, i no girà el rostre; ja era prou per a la seva mort àdhuc una sola ferida, però Filomela li tallà el coll amb el ferro; els membres són vius encara i retenen alguna cosa de l'ànima, que ja els hi esqueixen: una part salta en la concavitat del bronze, una altra espetega els astos; la cambra regalima sang corrompuda ${ }^{67}$.]

Ara bé, Roís de Corella es recrea en tres detalls efectistes absents en el seu model: a) la mort s'executa no amb una espasa qualsevol sinó amb la del pare; b) uns troços de l'infant es destinen a ser bollits en les olles, mentre que uns altres són rostits en astos, i c), el més impactant, la resistència que presenten les flames a ser còmplices d'una operació tan macabra, d'acord amb l'habitual exercici interactiu entre la naturalesa humana $\mathrm{i}$ els elements inànimes tan recurrent en el nostre autor.

Però la mort de l'infant no és més que la primera passa del pla de les dues dones. En efecte, Procne consuma la seua venjança convidant el seu marit a un banquet privat, les viandes del qual no són

${ }^{67}$ Ovidi, Metamorfosis, cit., II, p. 22. 
altres sinó les carns del seu fill mort ${ }^{68}$. Així ho descriu l'autor valencià en aquesta escena truculenta en la qual no escatima ni el més mínim element morbós:

Començà lo rey, ab les cruels dents, de son fill la rostida carn squinçar, les quals masteguar no podien, refusant tan feroce crueldat cometre. La sua gola se strenyia per no donar passatge que dins les seues entramenes les masteguades carns de son fill se amaguassen. Demanà l'ignorant rey a beure per donar passatge a la mísera vianda, al qual portà Prognes la copa ab lo vi part de la sanch del trocegat infant mesclada. La mà de Thereu, no sabent, tremolava; l'or se descoloria e l'enmetzinat vi, dels seus llabis fogint, ab gran afany dins lo ventrell pasava. E la ita de Prognes mitigar no·s podia.

Gran part del fill rostit Thereu menjava, quant, afectadament, demanà de l'amat príncep, dient que lo y portassen, al qual, sens tarda, respòs Prognes: «Ja tens lo que demanes». E, mirant lo miserable pare per tota la cambra si $\cdot 1$ fill poguera veure, davant la sua taula -de son fill sepulcre- stigué Philomena, tenint per los cabells lo cap del menjat infant, lo qual lançant a la cara de Thereu, fon la ora que ab major enuig li falliren paraules, perquè Prognes, ab irada veu parlant, lo miserable present acompanyava (p. 281).

La comparació amb la seqüència pertinent de les Metamorfosis (VI, vv. 650-660) palesa que, en aquest cas, Joan Roís de Corella l'ha amplificat al màxim mitjançant la incorporació d'ingredients conceptuals $i$ retòrics d'una superior eficàcia commovedora $i$ susceptibles de provocar un major impacte emocional. Comprovem-ho, si no:

Ipse sedens solio Tereus sublimis auito

Vescitur inque suam sua uiscera congerit aluum,

Tantaque nox animi est: 'Ityn huc accersite' dixit.

Dissimulare nequit crudelia gaudia Procne

Iamque suae cupiens existere nuntia cladis:

'Intus habes, quem poscis' ait. circumspicit ille

Atque, ubi sit, quaerit: quaerenti iterumque uocanti,

Sicut erat sparsia furiali caede capillis,

Prosiluit Ityosque caput Philomela cruentum

Misit in ora patris nec tempore maluit ullo

Posse loqui et meritis testari gaudia dictis.

${ }^{68}$ La mitologia clàssica documenta altres dos banquets semblants: el de Licàon i el de Tàntal. A aquest propòsit, vid., per exemple, Rosa M. Iglesias i M. Consuelo Álvarez, «Banquetes míticos intencionados», Actas del $5^{\circ}$ Coloquio de Estudiantes de Filología Clásica. Vino y Banquete en la Antigüedad (Valdepeñas 7, 8 y 9 de julio de 1993), Valdepeñas, Centro Provincial Asociado de la UNED «Lorenzo Luzuriaga», 1993, pp. 43-62. 
[Ell mateix, seient encimbellat al soli dels avis, Tereu menja i acumula les seves pròpies entranyes dins el seu ventre; i tanta és la nit de la seva ànima que: «Dueu-me Itis ací!» digué. No vol dissimular Procne el goig cruel i cobejosa de posar-se a anunciar la seva destroça: «A dintre tens qui demanes» diu. Mira ell al seu voltant i cerca on és. Mentre cerca i el crida de nou, tal com estava, amb els cabells esquitxats de la folla matança, saltà Filomela i llançà el cap sagnant d'Itis a la faç del seu pare; i en cap temps no desitjà tant poder parlar i testimoniar el seu goig amb les paraules que ell es mereixia. $]^{69}$

De l'acarament de les dues seqüències es deriven dues diferències fonamentals:

1) La sintètica referència ovidiana al fet que «Tereu menja i acumula les seves pròpies entranyes dins el seu ventre», es desenvolupa enormement i d'una manera molt efectista en Roís de Corella, mitjançant el recurs patètic, ja esmentat anteriorment, de la interacció dels elements inanimats, els quals es resisteixen a ser còmplices de l'horror: «Començà lo rey, ab les cruels dents, de son fill la rostida carn squinçar, les quals masteguar no podien, refusant tan feroce crueldat cometre. La sua gola se strenyia per no donar passatge que dins les seues entramenes les masteguades carns de son fill se amaguassen».

2) Corella hi afegeix un element nou, la al·lusió a la no menys macabra beguda del banquet, que tampoc es documenta en la font ovidiana: «Demanà l'ignorant rey a beure per donar passatge a la mísera vianda, al qual portà Prognes la copa ab lo vi part de la sanch del trocegat infant mesclada».

Els dos elements diferencials assenyalats, absents també en el relat corresponent de les Genealogiae (IX, cap. VIII) ${ }^{70}$, és molt probable que s'hagen inspirat en una altra tragèdia de Sèneca, Thyestes, assenyalada per Martos ${ }^{71}$ com a possible font corellana. En aquesta obra, Atreu, rei de Micenes, es venja de l'adulteri comés pel seu germà Tiestes amb la seua dona Aèrope, matant-li els seus tres fills $i$ servint-li-los com a menjar en un banquet sinistre:

La vianda és portada a Tiestes, pare infortunat; troceja los corsos de sos ffills propis e menja les carns ab la sua boqua miserable. [...] Beu-se la sanch de sos ffills. E moltes vegades la vianda se parava en la gola no podent passar ${ }^{72}$.

\footnotetext{
${ }^{69}$ Ovidi, Metamorfosis, cit., II, p. 22.

${ }^{70} \mathrm{Cfr}$. ed. cit., p. 540 .

${ }^{71}$ «Sèneca i Roís de Corella», cit., pp. 133-135.

${ }^{72}$ Sèneca, op. cit., I, p. 202.
} 


\section{A TALL DE CONCLUSIÓ}

Més enllà dels temes conceptualment morbosos d'una bona part de les faules mitològiques de Corella (incestos, parricidis, bestialitats...), l'autor també palesa una clara tendència a la morbositat com a pràctica retoricoestilística, especialment aplicada al tractament dels passatges més àlgids d'alguns d'aquests relats. Mentre que la morbositat dels temes li venia donada pels models i fonts en què es basava, no sempre podem dir el mateix quant a la morbositat referida a l'estil, generalment molt superior a la d'aquells. A tal efecte, de l'acarament dels textos corellans aportats amb les obres que els van poder servir de referència inspiradora, sembla que podem deduir un modus operandi predominant resumible en tres fets:

1a. En les seqüències més àlgides de les faules mitològiques, Joan Roís de Corella tria, de les fonts disponibles per a cada cas, aquelles que ofereixen un major detallisme morbós.

2a. Sense perjudici d'això, l'autor, gairebé sistemàticament, tendeix a intensificar aquest detallisme amb profusió i intensitat.

3a. I, encara més, quan estima insuficient el grau de morbositat que subministren les fonts de referència $i$ les seues pròpies amplificacions retòriques en una seqüència concreta, no dubta a afegir-hi subseqüències de factura pròpia capaces de compensar en aquest aspecte els models en què es basa.

Amb aquesta tècnica, unida al munt d'altres recursos que no toca tractar ací, el primer Joan Roís de Corella, en aquests exercicis jovenívols que són les seues proses mitològiques, tot partint de la pràctica escolar tardomedieval de la imitatio dels auctores, aconsegueix uns productes força originals, en els quals l'efectisme dels detalls morbosos contribueix a incrementar la capacitat de commoció anímica del receptor i, al capdavall, de posar al seu abast unes propostes morals perfectament assumibles des d'una òptica cristiana. 


\title{
$\cos$
}

\section{LA INTENSIFICACIÓ RETÒRICA DELS ELEMENTS MORBOSOS EN LES FAULES MITOLÒGIQUES DE JOAN ROÍS DE CORELLA: DE LA IMITATIO A LA INNOVACIÓ ESTÈTICA}

\begin{abstract}
RESUMEN: Les faules mitològiques, amb les quals Roís de Corella inicia la seua carrera literària, són exercicis escolars destinats a l'ensinistrament en l'escriptura en prosa. Cadascun d'aquests textos reescriu, amb trets originals, un tema ja tractat anteriorment per autors prestigiosos. Una de les innovacions que hi aporta Roís de Corella és l'amplificació retòrica de les seqüències més morboses d'aquestes faules, dins d'una proposta estètica caracteritzada per l'exacerbació sentimental i l'efectisme. Així es dedueix de l'acarament d'algunes de les seqüències més tràgiques d'una selecció d'aquests relats (el Plant dolorós de la reina Hècuba, la lletra de Medea, la lamentació de Mirra i les històries de Pasífae i de Tereu, Procne i Filomela) amb els models literaris corresponents.
\end{abstract}

PARAUles ClaU: Roís de Corella, faules mitològiques, elements morbosos, intensificació retòrica, models literaris.

\section{RHETORIC INTENSIFICATION OF MORBID ELEMENTS IN THE MYTHOLOGICAL TALES BY JOAN ROÍS DE CORELLA: FROM THE IMITATIO TO THE AESTHETIC INNOVATION}

ABSTRACT: The mythological tales, with whom Roís de Corella began his literary career, are school exercises for training in prose writing. Each of these texts is dedicated to rewrites, with original features, a subject previously dealt by prestigious authors. One of the innovations that Roís de Corella offers is a rhetorical amplification of the more ghoulish sequences of these fables, in an aesthetic proposal characterized by sentimental exacerbation and sensationalism. This is deduced from the comparison between some of the most tragic sequences of a selection of these short stories (the Plant dolorós de la reina Hècuba, Medea letter, lamentation of Mirra and the stories of Pasífae and Tereu and of Procne and Filomela) with their corresponding literary models.

KEYwORDs: Roís de Corella, mythological tales, ghoulish elements, intensifying rhetoric, literary models. 